\title{
Effect of Apple Rootstocks on Average 'Gala' Fruit Weight at Four Locations after Adjusting for Crop Load
}

\author{
Richard P. Marini and John A. Barden \\ Department of Horticulture, Virginia Polytechnic Institute and State University, Blacksburg, VA 24061 \\ John A. Cline \\ Department of Plant Agriculture, University of Guelph, PO Box 587, Simcoe, Ontario N3Y 4N5 Canada \\ Ronald L. Perry \\ Department of Horticulture, Michigan State University, East Lansing, MI 48824-1325
}

\author{
Terence Robinson \\ Department of Horticultural Sciences, New York State Agricultural Experiment Station, Cornell University, \\ Geneva, NY 14456
}

\begin{abstract}
ADDITIONAL INDEX WORDS. Malus sylvestris var. domestica, crop density, analysis of covariance, least squares means
ABSTRACT. The influence of rootstock on average fruit weight was evaluated for a subset of data from a multilocation NC-140 apple [Malus sylvestris (L.) Mill. var. domestica (Borkh.) Mansf.] rootstock trial. Data for eight dwarf rootstocks were collected at four locations for 2 years. Analysis of covariance was used to evaluate the effect of rootstock on average fruit weight when crop density or number of fruit per tree was included in the linear model as a covariate. When number of fruit harvested per tree was used as a covariate, average fruit weight was not affected by rootstock in either year in Ontario. In Michigan and Virginia, rootstock and number of fruit per tree, but not the rootstock $\times$ number of fruit interaction, were significant, so common slopes models were used to estimate least squares means for average fruit weight. In general, trees on M.27 and P.1 produced the smallest fruit, and trees on B.9, M.9 EMLA, and Mac.39 produced the largest fruit. In New York the interaction of rootstock $\times$ number of fruit was significant, so least squares means were estimated at three levels of number of fruit per tree. Both years, at all levels of number of fruit, trees on M.26 EMLA produced the smallest fruit and trees on M.27 EMLA produced the largest fruit. Average fruit weight was most affected by number of fruit per tree when Mark was the rootstock. In general, results were similar when crop density was used as the covariate, except that trees on M.27 EMLA did not produce small fruit in Michigan and Ontario.
\end{abstract}

Apple orchard profitability depends on producing high yields of marketable fruit. Markets for fresh and processing fruit generally require apples $>63 \mathrm{~mm}$ in diameter: smaller fruit bring juice prices. Because fruit size and yield are so important, rootstock researchers routinely record yield as well as average fruit weight and other indices of fruit quality. The ideal rootstock should induce good tree survival, high annual yields, and acceptable fruit size. In previous studies, the effect of rootstock on fruit size was inconsistent. Some researchers reported that average fruit weight was affected by rootstock (Autio, 1991; Jackson and Blasco, 1975; Preston et al., 1981), whereas others reported little effect (Barden and Marini, $1997,1999,2001 ; \mathrm{NC}-140,1996)$. In one of the NC-140 trials, trees on seedling, P.22 and B.9 produced the smallest fruit and trees on C.6 produced the largest fruit (NC-140, 1996). However, one factor that complicates evaluation of a rootstock effect on fruit weight is the crop load, which may vary with rootstock and with year. Vigorous rootstocks tend to have high numbers of fruit per tree, but relatively low crop density (fruit $/ \mathrm{cm}^{2}$ trunk cross-sectional area). For trees of similar size, average fruit weight is negatively related to the number of fruit per tree and crop density (Elfving and Schecter, 1993; Forshey and Elfving, 1977).

More precise estimates of average fruit weight can be obtained by using analysis of covariance, where the variation in fruit weight that is associated with crop load is removed from the error variance. Analysis of covariance is a model containing both continuous variables $(\mathrm{CD})$ and group indicator variables (rootstocks). Means that are adjusted for the covariate or least squares means can then be compared with a multiple comparison. Least squares means, ad-

Received for publication 18 Jan 2002. Accepted for publication 17 June 2002. justed for $\mathrm{CD}$, were reported for several rootstock experiments (Autio, 1991; Barritt et al., 1995, 1996, 1997; Marini et al., 2001).

Another way to view analysis of covariance is as a method to compare a series of regression models. When analysis of covariance is used to produce least squares means, we assume 1) there exists a linear relationship between the covariate ( $\mathrm{CD}$ for example) and the response variable (average fruit weight); 2) the relationship between the response variable and the covariate is the same for each treatment (rootstock); 3) the covariate is not affected by treatment; and 4) the observations come from a normal distribution (Hinkelmann and Kempthorne, 1994). To test the second assumption, homogeneity of slopes can be evaluated by including in the model an interaction term for the indicator variable $\times$ covariate; in this case the interaction term is rootstock $\times \mathrm{CD}$. A nonsignificant interaction term indicates that there is a series of parallel lines that can be compared by estimating the distance between them. Adjusted means are predicted values obtained from the estimated regression lines evaluated at the mean value of the covariate (Littell et al., 1996). A significant interaction, as recently reported for several rootstock experiments (Marini et al., 2000a, 2000b, 2001), indicates that the slopes are not equal. When the interaction is significant, analysis of covariance should not be used (Steele and Torrie, 1980). Until recently, the next step in the analysis would involve fitting regression models for each level of the indicator variable; in other words a regression model would be fit for each rootstock (Neter et al., 1990). Such an approach is not ideal when the experimental design has restrictions on randomization such as blocks. There is no way to account for blocks in a regression model, so the error term would contain both residual error as well as variation due to blocks. Enhancements to SAS's Mixed Procedure allow one to specify the appropriate model in an analysis 
of covariance and to estimate regression models for each rootstock. To facilitate interpretation of analysis of covariance when the slopes are unequal, the models can be compared at a minimum of three values of CD because the value of the adjusted average fruit weight depends on the value of CD (Littell et al., 1996). This type of analysis can be performed with the "test at" option in SAS's Mixed Procedure (Littell et al., 1996).

This study was undertaken to evaluate the influence of eight dwarf apple rootstocks on average fruit weight in two seasons at four locations. Analysis of covariance was used to remove the variation in average fruit weight due to $\mathrm{CD}$ or number of fruit per tree. This paper also demonstrates one strategy for determining the covariate part of an analysis of covariance model for a factorial experiment in a randomized complete block design (RCBD).

\section{Materials and Methods}

Data for this study were from the 1990 NC-140 dwarf rootstock trial with 'Gala' as the scion cultivar, and details concerning the trial were published (Marini et al., 2001). Data were obtained from cooperators at Michigan, New York, Ontario, and Virginia. The experiment was a replicated RCBD (Hinkelmann and Kempthorne, 1994), because there was a RCBD at each location. Eight dwarf rootstocks (Mac.39, P.1, O.3, M27 EMLA, B.9, M.26 EMLA, Mark, and M.9 EMLA) were compared at each location, where groups of six trees per rootstock were assigned randomly to 10 -m-long sections of row within each of four blocks. Data were recorded for the four interior trees and the end trees served as buffers. Therefore, at each location there were 16 data trees per rootstock and the experimental unit was the fourtree plot. Trunk cross-sectional area (TCA), yield ( $\mathrm{kg} / \mathrm{tree})$, the number of fruit per tree, and the estimated average fruit weight were recorded for each tree for the ninth and tenth years of the experiment.

STATISTICAL ANALYSES. Initially an analysis of variance was performed on the entire data set. Data were then analyzed by location because the location $\times$ rootstock $\times$ year interaction was significant $(\mathrm{F}=4.83, P=0.001, \mathrm{df}=52)$ and because variances were not equal. The effect of rootstock on average fruit weight was evaluated with analysis of covariance. There are several approaches for determining the form of the covariate part of the model, and the strategy suggested by Littell et al. (1996) was used as outlined below, where number of fruit harvested per tree (NF) was used as the covariate. In all models the block and block $\times$ rootstock $\times$ year terms were declared as random effects.

Step 1 . Test the hypothesis that all slopes are equal to zero with the following model:

\section{$\mathrm{FW}=$ STOCK YEAR STOCK*YEAR NF*STOCK*YEAR}

a) If fail to reject (NF*STOCK*YEAR not significant), go to step 3; b) If reject (NF*STOCK*YEAR significant), go to step 2; where FW is the average fruit weight (g/fruit), stock is the rootstock, year is either 1998 or 1999, and NF is the number of fruit per tree and is the covariate.

Step 2. Fit a model to test the hypothesis that the slopes are equal with the following model:

$\mathrm{FW}=\mathrm{STOCK}$ YEAR STOCK $*$ YEAR NF NF*STOCK*YEAR

a) If fail to reject (NF*STOCK*YEAR not significant), go to step 3;

b) If reject (NF*STOCK*YEAR is significant), go to step 4.
Step 3. Fit a common slope model and test the hypothesis that the slope is equal to zero with the following model:

$\mathrm{FW}=$ STOCK YEAR STOCK*YEAR NF

a) If fail to reject (NF is not significant), compare treatments with analysis of variance and compare means with a multiple comparison;

b) If reject (NF is significant), use the common slope model and compare the treatments by comparing the adjusted means (least squares means). This is a typical analysis of covariance.

Step 4. Fit the following unequal slopes model:

$\mathrm{FW}=$ STOCK YEAR STOCK*YEAR NF NF*STOCK*YEAR

a) Compare the slopes of the treatments;

b) Compare the models at a minimum of three values of NF. The Mixed Procedure supports an option to compare, using the probability of the difference (PDIFF), least squares means estimated for any level of a covariate.

A second set of analyses was also performed using CD as the covariate.

\section{Results}

General. The number of fruit per tree and the CD varied somewhat for location and year, but were most affected by rootstock (Table 1). Considering the raw data, the number of fruit per tree ranged from 69 to 412 . The number of fruit per tree was slightly lower for Ontario than for the other locations and trees were slightly over-cropped in Virginia in 1999 due to poor response to chemical thinning applications. In general CD ranged from 0.9 to 7.6. The highest values for CD were recorded in New York and Michigan in 1998. In Michigan and New York the fewest fruit were harvested from trees on P.1, but in Ontario and Virginia, the fewest fruit were harvested from trees on M.27. At all locations CD was lowest for trees on P.1 and M.26.

NuMBER OF FRUIT PER TREE (NF) AS A COVARIATE. For Michigan, Ontario, and Virginia, results from analysis of covariance, using NF as the covariate indicated that there was an interaction between rootstock and year, that slopes for the 16 rootstock/year combinations were not different, and that all slopes were not equal to zero. Therefore, for each location a common slope model was used to estimate least squares means for each year (Table 2). In contrast, for New York the hypothesis that all slopes were equal was rejected $(P$ $=0.001)$, so least squares means were estimated at three levels of NF $(100,211$, and 300 fruit per tree) for each year as suggested by Littell et al. (1996) (Table 3). These values were selected because the mean number fruit per tree in New York was 211, and represents the central value for the covariate. The other two values represented the lower and upper ends of the range for number of fruit per tree in New York. Average fruit weight, adjusted for FN, was affected by rootstock but the effect was not consistent for locations or years at the same location. In Michigan in 1998, trees on M.27 had the smallest fruit and trees on M.9 EMLA had larger fruit than trees on P.1 (Table 2). However in 1999 trees on P.1, O.3, and M.27 had the smallest fruit and differed significantly from trees on Mac.39, which had the largest fruit. In Ontario, rootstock did not affect average fruit weight in 1998; in 1999 P.1 and M.27 had significantly smaller fruit than Mac.39, O.3, B.9, and M.9. In Virginia in 1998 rootstocks fell into three fairly distinct groups. The smallest fruit were harvested from trees on P.1 and M.26; intermediate-size fruit were harvested 
from trees on Mac.39, O.3, B.9, and M.9; the largest fruit were harvested from trees on M.27. In 1999 fruit on M.26 were significantly smaller than fruit on Mac.39, and all other rootstocks were intermediate.

In New York, the influence of rootstock on average fruit weight depended on the number of fruit per tree (Table 3). In 1998 average fruit weight was not affected by rootstock when the number of fruit harvested per tree was 211 or 300, but when there were 100 fruit per tree, trees on Mac.39 and Mark produced significantly smaller fruit than trees on B.9. In 1999, when trees had 100 fruit per tree, P.1, M.26, and Mark produced significantly smaller fruit than trees on Mac.39, M.27, and B.9. When trees had 211 fruit per tree, trees on Mark produced significantly smaller fruit than trees on B.9. When 300 fruit were harvested per tree, rootstock did not significantly influence average fruit weight.
Crop density (CD) AS a Covariate. For Michigan, Ontario, and Virginia, results from analysis of covariance, using CD as a covariate, indicated that there was an interaction between rootstock and year, that slopes for the 16 rootstocks/year combinations were not different, and that slopes were not all equal to zero. Therefore, for each of these locations a common slope model was used to estimate least squares means for each year. As with NF, for New York the hypothesis that all slopes were equal was rejected $(P=0.003)$, so least squares means were estimated at three levels of CD $(3.0,4.5$, and 6.0 fruit $/ \mathrm{m}^{2}$ ). Average fruit weight, adjusted for CD, was not affected by rootstock in Ontario (Table 4). Rootstock influenced fruit weight in Michigan and Virginia, but results varied for location and year. In Michigan in 1998 trees on P.1 produced significantly smaller fruit than trees on Mac.39, B.9, Mark, and M.9 (Table 4). In Michigan in 1999 trees on P.1, O.3, and M.26 produced smaller fruit

Table 1. Mean values for number of 'Gala' fruit harvested per tree and crop density for eight dwarfing rootstocks at four locations for 2 years.

\begin{tabular}{|c|c|c|c|c|c|c|c|c|c|c|c|c|c|c|c|c|}
\hline \multirow[b]{2}{*}{ Rootstock } & \multicolumn{8}{|c|}{ Fruit/tree (no.) } & \multicolumn{8}{|c|}{ Crop density (fruit $/ \mathrm{cm}^{2} \mathrm{TCA}^{\mathrm{z}}$ ) } \\
\hline & 1998 & 1999 & 1998 & 1999 & 1998 & 1999 & 1998 & 1999 & 1998 & 1999 & 1998 & 1999 & 1998 & 1999 & 1998 & 1999 \\
\hline P.1 & 133 & 96 & 129 & 84 & 172 & 119 & 135 & 257 & 1.5 & 1.0 & 1.6 & 0.9 & 2.3 & 1.5 & 1.3 & 2.4 \\
\hline 0.3 & 225 & 194 & 328 & 195 & 176 & 154 & 153 & 296 & 3.6 & 2.7 & 6.3 & 3.3 & 3.9 & 2.9 & 2.2 & 3.8 \\
\hline M.27 EMLA & 216 & 255 & 162 & 134 & 93 & 82 & 69 & 119 & 7.6 & 7.5 & 5.9 & 4.5 & 4.2 & 3.5 & 1.9 & 3.3 \\
\hline Mark & 294 & 300 & 231 & 218 & 119 & 134 & 167 & 265 & 5.9 & 5.5 & 5.7 & 5.0 & 2.7 & 2.9 & 3.3 & 4.9 \\
\hline M.9 EMLA & 270 & 213 & 323 & 214 & 124 & 131 & 153 & 373 & 5.4 & 3.8 & 7.2 & 4.4 & 3.6 & 3.5 & 2.6 & 5.8 \\
\hline
\end{tabular}

ZTrunk cross-sectional area.

Table 2. The effect of eight dwarfing rootstocks at three locations on average 'Gala' fruit weight (g) in 1998 and 1999. Analysis of covariance was used to adjust the least squares means for number of fruit harvested per tree.

\begin{tabular}{|c|c|c|c|c|c|c|}
\hline \multirow[b]{2}{*}{ Rootstock } & \multicolumn{2}{|c|}{ Michigan } & \multicolumn{2}{|c|}{ Ontario } & \multicolumn{2}{|c|}{ Virginia } \\
\hline & 1998 & 1999 & 1998 & 1999 & 1998 & 1999 \\
\hline & \multicolumn{6}{|c|}{ Fruit wt $(\mathrm{g})$} \\
\hline P.1 & $140 \mathrm{~b}$ & $141 \mathrm{a}$ & $157 \mathrm{a}$ & $132 \mathrm{a}$ & $119 \mathrm{a}$ & $119 \mathrm{ab}$ \\
\hline 0.3 & $143 \mathrm{bc}$ & $148 \mathrm{ab}$ & $157 \mathrm{a}$ & $155 \mathrm{~b}$ & $122 \mathrm{~b}$ & $118 \mathrm{ab}$ \\
\hline M.27 EMLA & $128 \mathrm{a}$ & $141 \mathrm{a}$ & $144 \mathrm{a}$ & $137 \mathrm{a}$ & $163 \mathrm{c}$ & $112 \mathrm{ab}$ \\
\hline Mark & $144 \mathrm{bc}$ & $152 \mathrm{~b}$ & $158 \mathrm{a}$ & $148 \mathrm{ab}$ & $128 \mathrm{ab}$ & $110 \mathrm{ab}$ \\
\hline M.9 EMLA & $152 \mathrm{c}$ & $154 \mathrm{~b}$ & $155 \mathrm{a}$ & $166 \mathrm{~b}$ & $140 \mathrm{~b}$ & $116 \mathrm{ab}$ \\
\hline
\end{tabular}

${ }^{\mathrm{Z}}$ Least squares means separation within columns by PDIFF at a pair-wise error rate of $5 \%$.

Table 3. The effect of eight dwarfing rootstocks at New York on average 'Gala' fruit weight (g) in 1998 and 1999. Analysis of covariance was used to estimate least squares means at three levels of number of fruit per tree $(100,211$, and 300) each year.

\begin{tabular}{|c|c|c|c|c|c|c|}
\hline \multirow[b]{2}{*}{ Rootstock } & \multicolumn{3}{|c|}{1998} & \multicolumn{3}{|c|}{1999} \\
\hline & 100 & 211 & 300 & 100 & 211 & 300 \\
\hline P.1 & $159 \mathrm{ab}$ & $155 \mathrm{a}$ & $152 \mathrm{a}$ & $131 \mathrm{a}$ & $132 \mathrm{ab}$ & $134 \mathrm{a}$ \\
\hline 0.3 & $158 \mathrm{ab}$ & $152 \mathrm{a}$ & $148 \mathrm{a}$ & $136 \mathrm{ab}$ & $126 \mathrm{ab}$ & $118 \mathrm{a}$ \\
\hline M.27 EMLA & $157 \mathrm{ab}$ & $151 \mathrm{a}$ & $145 \mathrm{a}$ & $142 \mathrm{~b}$ & $127 \mathrm{ab}$ & $115 \mathrm{a}$ \\
\hline Mark & $147 \mathrm{a}$ & $150 \mathrm{a}$ & $152 \mathrm{a}$ & $119 \mathrm{a}$ & $119 \mathrm{a}$ & $119 a$ \\
\hline M.9 EMLA & $165 \mathrm{ab}$ & $154 \mathrm{a}$ & $145 \mathrm{a}$ & $136 \mathrm{ab}$ & $127 \mathrm{ab}$ & $121 \mathrm{a}$ \\
\hline
\end{tabular}

${ }^{\mathrm{Z}}$ Least squares means separation within columns by PDIFF at a comparison-wise error rate of 5\%. 
than trees on Mac.39 and B.9. In Virginia in 1998 trees on P.1 and M.26 produced significantly smaller fruit than trees on Mac.39, M.27, B.9, and M.9. Fruit on M.27 were significantly larger than fruit on all other rootstocks. In 1999 trees on M.26 had the smallest fruit, but differed significantly from only Mac.39, which had the largest fruit.

In New York in 1998, when average fruit weight was estimated for a $\mathrm{CD}$ of 3.0, M.26 produced the smallest fruit and M.27 produced the significantly larger fruit than all rootstocks except B.9 and Mark (Table 5). When CD was 6.0, trees on M.26 produced significantly smaller fruit than trees on Mac.39, M.27, and B.9. In 1999 when CD was 3.0 trees on M.26 and O.3 produced significantly smaller fruit than trees on M.27, B.9, and Mark. When the CD was 4.5 trees on M.26 and O.3 produced significantly smaller fruit than trees on M.27. When the CD was 6.0, trees on Mark produced significantly smaller fruit than trees on P.1 and M.27.

\section{Discussion}

Results from the present study are slightly different than results from previous studies. In other rootstock trials, average fruit weight was often inconsistently affected by rootstock. During the fourth and fifth years of the current study, after adjusting for crop load, rootstock influenced average fruit weight in only four of 16 location/ year combinations (Barritt et al., 1997). During the fourth year in New York the smallest fruit were produced by trees on P.1 and Mark; in Ontario P.1 produced the smallest fruit; and in Quebec P.1 and M.26 produced the smallest fruit. During the fifth year in Virginia, P.1 and Mark produced the smallest fruit (Barritt, et al. 1997). In several trials, the rootstocks that tended to produce the smallest fruit included P.1, Mark, and M.27 (NC-140, 1996; Barritt et al., 1995, 1997). During four years of a rootstock trial in Massachusetts, trees on OAR.1 consistently produced small fruit, whereas trees on M.9 EMLA produced large fruit, after adjusting for crop load (Autio, 1991). Results from other rootstock trials also indicate that trees on M.9 or M.9A produced larger fruit than trees on M.27, M.7, or MM.106 (Preston et al., 1981). In previous studies average fruit weight was either not adjusted for a covariate or analysis of covariance was used to adjust the means for CD. However, in most previous studies there was no indication that the interactions between the main effects and the covariate were evaluated, so means may not have been adjusted correctly. When the hypothesis that all slopes are equal was tested with data from three NC-140 trials, the location by rootstock by covariate interactions were always significant (Marini et al., 2000a, 2000b, 2001), indicating that the assumption that all slopes are homogeneous may not be valid in many multilocation rootstock experiments. In such cases it is not appropriate to use a normal analysis of covariance to adjust the means for a covariate.

It is not clear which index of crop load should be used as the covariate. Elfving and Schecter (1993) used regression to evaluate the relationship between average fruit weight and number of fruit per tree for nine rootstocks with a wide range of vigor in Ontario. Average fruit weight was better related to number of fruit per tree $\left(r^{2}\right.$ $=0.96)$ than crop density $\left(r^{2}=0.67\right)$. They also concluded that when average fruit weight was adjusted for crop load, rootstock did not influence average fruit weight because regression models for a given year were similar regardless of rootstock. However, there was no indication if homogeneity of slopes were formally tested by including a term for the interaction of rootstock $\times$ crop load in the

Table 4. The effect of eight dwarfing rootstocks at three locations on average 'Gala' fruit weight (g) in 1998 and 1999. Analysis of covariance was used to adjust the least squares means for crop density (fruit $/ \mathrm{cm}^{2}$ ).

\begin{tabular}{|c|c|c|c|c|c|c|}
\hline \multirow[b]{2}{*}{ Rootstock } & \multicolumn{2}{|c|}{ Michigan } & \multicolumn{2}{|c|}{ Ontario } & \multicolumn{2}{|c|}{ Virginia } \\
\hline & 1998 & 1999 & 1998 & 1999 & 1998 & 1999 \\
\hline & \multicolumn{6}{|c|}{ Fruit wt (g) } \\
\hline P.1 & $133 \mathrm{a}$ & $133 \mathrm{a}$ & $149 \mathrm{a}$ & $128 \mathrm{a}$ & $119 \mathrm{a}$ & $119 a b$ \\
\hline 0.3 & $140 \mathrm{ab}$ & $142 \mathrm{ab}$ & $156 \mathrm{a}$ & $151 \mathrm{a}$ & $122 \mathrm{ab}$ & $118 \mathrm{ab}$ \\
\hline M.27 EMLA & $140 \mathrm{ab}$ & $152 \mathrm{bc}$ & $153 \mathrm{a}$ & $146 \mathrm{a}$ & $163 \mathrm{c}$ & $112 a b$ \\
\hline Mark & $146 \mathrm{bc}$ & $151 \mathrm{bc}$ & $159 \mathrm{a}$ & $147 \mathrm{a}$ & $128 \mathrm{ab}$ & $110 \mathrm{ab}$ \\
\hline M.9 EMLA & $153 \mathrm{c}$ & $152 \mathrm{bc}$ & $159 a$ & $168 \mathrm{a}$ & $140 \mathrm{~b}$ & $116 \mathrm{ab}$ \\
\hline
\end{tabular}

${ }^{\mathrm{Z}}$ Least squares means separation within columns by PDIFF at a pair-wise error rate of $5 \%$.

Table 5. The effect of eight dwarfing rootstocks at New York on average 'Gala' fruit weight (g) in 1998 and 1999. Analysis of covariance was used to estimate least squares means three at levels of crop density (fruit $\left./ \mathrm{cm}^{2}\right)(3.0,4.5$, and 6.0) each year.

\begin{tabular}{|c|c|c|c|c|c|c|}
\hline \multirow[b]{2}{*}{ Rootstock } & \multicolumn{3}{|c|}{1998} & \multicolumn{3}{|c|}{1999} \\
\hline & 3.0 & 4.5 & 6.0 & 3.0 & 4.5 & 6.0 \\
\hline P.1 & $154 \mathrm{ab}$ & $149 a b$ & $146 \mathrm{ab}$ & $130 \mathrm{ab}$ & $130 \mathrm{ab}$ & $129 \mathrm{~b}$ \\
\hline 0.3 & $158 \mathrm{ab}$ & $153 \mathrm{ab}$ & $147 \mathrm{ab}$ & $129 a$ & $119 \mathrm{a}$ & $110 \mathrm{ab}$ \\
\hline M.27 EMLA & $182 \mathrm{c}$ & $167 \mathrm{~b}$ & $152 \mathrm{~b}$ & $148 \mathrm{~b}$ & $137 \mathrm{~b}$ & $126 \mathrm{~b}$ \\
\hline Mark & $169 \mathrm{bc}$ & $159 \mathrm{~b}$ & $149 \mathrm{ab}$ & $143 \mathrm{~b}$ & $125 \mathrm{ab}$ & $107 \mathrm{a}$ \\
\hline M.9 EMLA & $159 \mathrm{ab}$ & $153 \mathrm{ab}$ & $147 \mathrm{ab}$ & $135 \mathrm{ab}$ & $126 \mathrm{ab}$ & $118 \mathrm{ab}$ \\
\hline
\end{tabular}

${ }^{\mathrm{z} L e a s t}$ squares means separation within columns by PDIFF at a comparison-wise error rate of $5 \%$. 
model. In addition, the term for block could not be included in the regression model used by Elfving and Schecter (1993). Conclusions may have differed had an analysis of covariance been performed rather than simple linear regression for each rootstock. Results from the present study also indicate that in Ontario, rootstock did not influence average fruit weight, when fruit weight was adjusted for number of fruit per tree. As current NC-140 rootstock trials are concluded, it would be interesting to determine if Ontario is a unique location, or if rootstock has no influence on average fruit weight at other locations. In the present study, both covariates were significant, and usually gave similar results, but it is not possible to determine which covariate is best. When number of fruit was used as a covariate, the rootstocks that tended to produce the smallest fruit included M.27, P.1, and M.26, whereas the rootstocks that tended to produce the largest fruit included Mac.39 and B.9. When crop density was used as the covariate, P.1 and M.26 tended to produce the smallest fruit, whereas Mac.39, B.9, and M.27 tended to produce the largest fruit. Results for the two covariates were similar for all rootstocks except M.27, where the choice of the covariate greatly influenced estimates for average fruit weight. When means were adjusted for number of fruit per tree, M.27 produced small fruit, but when means were adjusted for crop density, M.27 produced large fruit. While performing similar data analyses for peach, average fruit weight seemed to be influenced by the interaction of trunk cross-sectional area (TCA) and number of fruit per tree (Marini, unpublished data). When hand thinned to ensure that all trees had similar crop densities, average fruit weight was highest on trees with the highest TCA and average fruit weight was not significantly related to $\mathrm{CD}$. A more complicated analysis of covariance involving more than one covariate in the same model may be needed to explain the results for M.27. Until the relationship between CD, TCA, and number of fruit per tree is better understood, rootstock researchers might consider evaluating the influence of rootstock on average fruit weight by performing analysis of covariance with more than one covariate.

The covariance approach used in this study allows estimation of slopes for each rootstock derived from the relationships between average fruit weight and CD for the New York data. This information allows researchers to determine if some rootstocks can carry larger crops without sacrificing fruit size. In New York, P.1 was somewhat unique because trees on P.1 had much lower CDs than all other rootstocks (Table 1). The CD for P.1 may have been too low to have much of an effect on average fruit weight, because average fruit weight declined only $2.6 \mathrm{~g}$ and $0.3 \mathrm{~g}$ for each unit increase in CD in 1998 and 1999, respectively. In 1998 the three rootstocks with the highest CDs were Mac.39, O.3, and M.9, and the slopes were$3.0,-3.7$, and -4.0 , respectively. M.26 and B.9 had relatively low CDs, but slopes were -6.7 and -3.0 , respectively. Therefore, as CD increased, average fruit weight declined more for M.26 than for B.9. In 1999 Mac.39 and Mark had the highest CDs and their slopes were -7.7 and -12.0 , respectively. Based on the 2 years' data, Mac.39 appears most capable of carrying higher crop loads with minimal loss of fruit size than other rootstocks.

In this study crop load was limited to a fairly narrow range to ensure annual cropping. Results from the analysis of covariance may have differed had there been a wider range of crop load. To obtain data to better study the effect of rootstock on average fruit weight, researchers might consider continuing a rootstock study for an additional 2 years and thin trees to discrete crop densities ranging from 1.0 to 9.0 fruit $/ \mathrm{cm}^{2}$.

\section{Literature Cited}

Autio, W.R. 1991. Rootstocks affect ripening and other qualities of 'Delicious' apple. J. Amer. Soc. Hort. Sci. 116:378-382.

Barden, J.A. and R.P. Marini. 1997. Growth and fruiting of a spur-type and a standard strain of 'Golden Delicious' on several rootstocks over eighteen years. Fruit Var. J. 51:165-175.

Barden, J.A. and R.P. Marini. 1999. Rootstock effects on growth and fruiting of a spur-type and a standard strain of 'Delicious' over eighteen years. Fruit Var. J. 53:115-125.

Barden, J.A. and R.P. Marini. 2001. Yield, fruit size, red color, and estimated crop value in the NC-140 1990 cultivar/rootstock trial in Virginia. J. Amer. Pom. Soc. 55:150-158.

Barritt, B.H., J.A. Barden, J. Cline, R.L. Granger, M.M. Kushad, R.P. Marini, M. Parker, R.L. Perry, T. Robinson, C.R. Unrath, and M.A. Dilley. 1997. Performance of 'Gala' at year 5 with eight apple rootstocks in an 8-location North American NC-140 trial. Acta Hort. 451:129135 .

Barritt, B.H., B.S. Konishi, and M.A. Dilley. 1995. Performance of three apple cultivars with 23 dwarfing rootstocks during 8 seasons in Washington. Fruit Var. J. 49:158-170.

Barritt, B.H., B.S. Konishi, and M.A. Dilley. 1996. Performance of three apple cultivars with 18 vigorous rootstocks during nine seasons in Washington. Fruit Var. J. 50:88-98.

Elfving, D.C. and I. Schechter. 1993. Fruit count, fruit weight, and yield relationships in 'Delicious' apple trees on nine rootstocks. HortScience 28:793-795.

Forshey, C.G. and D.C. Elfving. 1977. Fruit numbers, fruit size, and yield relationships in 'McIntosh' apples. J. Amer. Soc. Hort. Sci. 102:399-402.

Jackson, J.E. and A.B. Blasco. 1975. Effects of rootstock and crop load on fruit size and quality of Cox's Orange Pippin and Worcester Pearmain. Rpt. E. Malling Res. Sta., 1974. p .45.

Hinkelman K. and O. Kempthorne. 1994. Design and analysis of experiments. Wiley, New York, N.Y.

Littell, R.C., G.A. Milliken, W.W. Stroup, and R.D. Wolfinger. 1996. SAS system for mixed models. SAS Institute Inc., Cary, N.C.

Marini, R.P., J.L. Anderson, W.R. Autio, J. Cline, W.P. Cowgill, Jr., R.M. Crassweller, P. A. Domoto, D.C. Ferree, J. Garner, A. Gauss, G.M. Greene, C. Hampson, P. Hirst, M.M. Kushad, E. Mielke, C.A. Mullins, M. Parker, R.L. Perry, J.P. Privé, G.L. Reighard, T. Robinson, C.R. Rom, T. Roper, J.R. Schupp, E. Stover, and R. Unrath. 2000a. Performance of 'Gala' apple on 18 dwarf rootstocks: A five-year summary of the 1994 NC-140 dwarf rootstock trial. J. Amer. Pomol. Soc. 54:92-107.

Marini, R.P., J.L. Anderson, B.H. Barritt, G.R. Brown, J. Cline, W.P. Cowgill, Jr., P. A. Domoto, D.C. Ferree, J. Garner, G.M. Greene, C. Hampson, P. Hirst, M.M. Kushad, E. Mielke, C.A. Mullins, M. Parker, R.L. Perry, J.P. Privé, G.L. Reighard, T. Robinson, C.R. Rom, T. Roper, J.R. Schupp, E. Stover, and R. Unrath. 2000b. Performance of 'Gala' apple on four semi-dwarf rootstocks: A five-year summary of the 1994 NC-140 semi-dwarf rootstock trial. J. Amer. Pomol. Soc. 54:84-91.

Marini, R.P., B.H. Barritt, J.A. Barden, J. Cline, R.L. Granger, M.M. Kushad, M. Parker, R.L. Perry, T. Robinson, S. Khanizadeh, and C.R. Unrath. 2001. Performance of 'Gala' apple on eight dwarf rootstocks: Ten-year summary of the 1990 NC-140 rootstock trial. J. Amer. Pomol. Soc. 55:197-204.

NC-140. 1996. Performance of the NC-140 cooperative apple rootstock planting. I. Survival, tree size, yield and fruit size. Fruit Var. J. 50:611.

Neter, J., W. Wasserman, and M.H. Kutner. 1990. Applied linear statistical models. $3^{\text {rd }}$ ed. Irwin, Inc., Boston, Mass.

Preston, A.P., D.E. Belcher, and B.C. Ley. 1981. Apple rootstock studies: Bramley's Seedling on dwarfing clones. Expt. Hort. 32:18-24.

Steele, R.G.D. and J.H. Torrie. 1980. Principles and procedures of statistics. $2^{\text {nd }}$ ed. McGraw-Hill Book Co., New York. 